\section{Working without}

\section{a nurse}

I am a dental hygienist, having qualified five years ago. I have worked in nine different practices as a hygienist: one practice since qualifying and others as a casual member of staff. I have been communicating with other hygienists on the internet across the country via Facebook.

On one of the sessions online, I wrote that I do not work with a nurse. I am given the assistance of a nurse to help when pocket charting is required or if I am struggling with aspiration. This is not on a regular basis though. I was struck by how many hygienists commented on me working without a nurse. Statements such as 'you cannot give your patients $100 \%$ without a nurse', 'medico-legally you won't stand a chance if a complaint comes against you and you don't have a chaperone', 'wouldn't dream of working without one' or 'you shouldn't be working without one' and so on.
From experience I have found working with a nurse, when essential, makes my role easier. After the string of messages I received regarding this, I felt the pressing need to find out how many general dental practices in the area I work, did provide a nurse for their hygienist. The areas I covered were Tunbridge Wells (23 practices), Tonbridge (6) and Sevenoaks (6).

I had responses from 28 practices. Only three of these practices supplied a nurse for assisting their hygienist (one in Tonbridge and two in Tunbridge Wells). One practice did not have a hygienist at all. In all of the other surgeries the hygienist worked alone. Seven practices did not participate. They either would not answer the phone (though multiple calls were made over a period of days) or they declined to answer my question on whether they supplied a nurse for their hygienist.

Kirsty Ranger

Dental Hygienist

\title{
ADDITIONS TO DCP COURSE DIRECTORY
}

The next Vital DCP course directory will be published in summer 2012.

\section{Cotswold training}

Thank you very much for including our Cotswold Dental Training NEBDN certificate course in the recent DCP course directory (Vital summer 2011; pages 15-20). Unfortunately the email address was incorrect and I would like to provide a telephone number:

Contact: Jackie Gazzard

Email: jackiegazzard@hotmail.co.uk

Website: www.cotswolddentaltraining.co.uk Phone: 07762241138 or 01453883867

Courses provided:

- NEBDN certificate course

- Dental nurse foundation training

- NEBDN Oral Health Education certificate course

- Dental Radiography

- CPD courses

\section{Jackie Gazzard RDN LCGI FBADN CFET Senior Tutor Cotswold Dental Training NEBDN Examiner}

South West Post Graduate Dental Deanery DCP Advisor Wilts/Dorset

\section{Nursing in Cardiff}

Would it be possible for you to add the two dental nurse training courses we offer at Cardiff University Dental Hospital to your DCP course directory?

The University Dental Hospital of Wales, Cardiff provides the Level 3 Diploma in Dental Nursing for both internal and external candidates. Internal applications must be received by the end of March for the August intake. The external intake, for trainee dental nurses working in general dental practice, is open all year.

Contact: Anna Barrett on 02920746495 or email anna.barrett@wales.nhs.uk or Penny Barker on 02920 748303, email: penny. barker@wales.nhs.uk.

\section{Penny Barker}

Lead NVQ Assessor/Tutor

University Dental Hospital, Cardiff

\section{Ayrshire and Arran}

I would be grateful if you would include us in your list of providers for SVQ in Dental Nursing level 3. We are NHS Ayrshire and Arran and our details are as below.

\section{Susan McGregor}

Dental Nurse Education Coordinator

Dental Nurse Education, Rooms 97-99,

Horseshoe Building, Ayrshire Central

Hospital, Irvine, KA12 8SS

Email: susan.mcgregor1@nhs.net

Tel: 01292323457 Mobile: 07825227821

\section{Certificates and CPD}

We would very much like to be included in your next course list. At Reading, Newbury, Oxford and Basingstoke we offer:

- Nat Cert in Dental Nursing
Snail mail: Vital Editorial, NPG, 4-6 Crinan Street, London N1 9XW Next issue's star letter writer will win Beverly Hills Formula goodies worth £100. Letters may be edited for space. Opinions expressed do not necessarily reflect those of the editorial team or publishers. 